\title{
DINÂMICA DE COBERTURA DE DOSSEL DE POVOAMENTOS DE CLONE DE Eucalyptus grandis W. Hill ex-Maiden SUBMETIDOS A DESRAMA ARTIFICIAL E DESBASTE ${ }^{1}$
}

\author{
Rogério de Araújo Chaves ${ }^{2}$, Maria das Graças Ferreira Reis ${ }^{3}$, Geraldo Gonçalves dos Reis ${ }^{3}$, José Eduardo \\ Macedo Pezzopane ${ }^{4}$, Aloisio Xavier ${ }^{3}$ e Marco Antonio Monte ${ }^{2}$
}

\begin{abstract}
RESUMO - A dinâmica de copa foi avaliada através do índice de área foliar (IAF), transmitância da radiação fotossinteticamente ativa ( $t \%$ ) e índice de cobertura do dossel (ICD), entre 55 e 68 meses de idade, em povoamentos de clone de Eucalyptus grandis desramados entre 16 e 45 meses de idade até a altura de $6 \mathrm{~m}$. Esses povoamentos foram submetidos a desbaste ( 0 e $35 \%$ do número total de mudas plantadas), aos 55 meses de idade, em Abaeté, MG. Não foi observada diferença significativa $(P \geq 0,05)$ entre os tratamentos de desrama, para IAF, $t \%$ e ICD, entre 55 e 68 meses de idade, em razão da elevada capacidade de recomposição de copa desse clone. Porém, observou-se mudança significativa $(\mathrm{P} \leq 0,05)$ nesses parâmetros entre as idades de avaliação, e houve redução de IAF e ICD e aumento de t\% imediatamente após o desbaste, tendo havido pronta recomposição da copa seis meses após o desbaste, nas três idades de primeira intervenção de desrama. Aos 68 meses de idade, o IAF e o ICD do povoamento desbastado foram significativamente $(\mathrm{P} \leq 0,05)$ maiores, enquanto $t \%$ foi significativamente menor do que do povoamento não-desbastado. Os resultados de IAF e t\% indicaram que essas informações podem ser utilizadas para avaliação da dinâmica de copa, sendo os dados de IAF mais consistentes do que os de $\mathrm{t} \%$. A utilização de fotografia digital apresenta potencial para avaliar a dinâmica de cobertura do dossel, em razão de ser um método de uso fácil e barato, embora ainda requeira aperfeiçoamentos.
\end{abstract}

Palavras-chave: Índice de área foliar, transmitância da radiação fotossinteticamente ativa e fotografias digitais.

\section{DYNAMIC OF CROWN COVER OF Eucalyptus grandis W. Hill ex Maiden CLONE STANDS AFTER PRUNING AND THINNING}

\begin{abstract}
Crown dynamic based on leaf area index (LAI), photosynthetic active radiation transmitancy $(t \%)$ and crown cover index (CCI) of Eucalyptus grandis clone stands was studied in southeastern Brazil. Plants were submitted to various pruning intensities and frequencies, starting at the age of 16, 20 and 28 months, up to 45 months, to reach 6 m pruned trunk. Thinning was applied at the age of 55 months by removing $0 \%$ (control) and $35 \%$ of the total number of planted trees. There was no significant $(P \geq O .05)$ difference among pruning treatments for LAI, $t \%$ and CCI. LAI decreased from 2.75 to 1.98 , immediately after thinning. A significant $L A I$ recovery $(P \leq O .05)$ was verified six months after thinning. LAI of the control was $29.3 \%$ higher than that of the thinned forest, at the age of 68 months indicating that by the age thinning was applied, the trees were still capable of expanding their crown. Photosynthetic active radiation transmitancy increased from 11.9 to $22.7 \%$, shortly after thinning, reducing to $16.8 \%$ at the age of 68 months due to leaf recover.
\end{abstract}

\footnotetext{
${ }^{1}$ Recebido em 07.03.2006 e aceito para publicação em 07.05.2007.

${ }^{2}$ Programa de Pós-Graduação em Ciência Florestal da Universidade Federal de Viçosa -UFV. E-mail: <rogerio-chaves@ plantar.com.br> e<marcoantoniomonte@yahoo.com.br>.

${ }_{3}^{3}$ Departamento de Engenharia Florestal da UFV. E-mail: <mgfreis@ufv.br>; <greis@ufv.br> e <xavier@ufv.br>.

${ }^{4}$ Departamento de Engenharia Rural da Universidade Federal do Espírito Santo-UFES. E-mail: <jemp@ cca.ufes.br>.
} 


\begin{abstract}
In the non-thinned forest, $t \%$ was $9.6 \%$, value significantly $(P \geq 0.05)$ smaller than that observed in the thinned forest (16.8\%). CCI (digital photograph method), at the age of 55 months reduced after thinning, from 0.83 to 0.69 , and to 0.70 at the age of 68 months, showing that this method was less sensitive to evaluate crown dynamics, if compared to LAI and $t \%$. In the non-thinned forest, CCI was 0.79 , significantly $(P \geq 0.05)$ higher than that observed for the thinned forest at the age of 68 months. The overall results indicated that LAI and photosynthetic active radiation transmitancy are suitable for crown dynamic evaluation, with the LAI data being more consistent. The method using digital photograph is inexpensive and easy to use, although it still requires improvement.
\end{abstract}

Keywords: Leaf area index, photosynthetic active radiation transmitancy and digital photographs.

\section{INTRODUÇÃO}

A adoção de técnicas silviculturais, como a desrama artificial e o desbaste, é de extrema importância para a obtenção de madeira de qualidade para serraria. Quando adequadamente programada e conduzida, a desrama artificial melhora substancialmente as propriedades físicas da madeira, principalmente por reduzir nós vivos e mortos (PIRES, 2000; PULROLNIK, 2002; VALE et al., 2002; ALMEIDA, 2003; POLLI et al., 2006). No entanto, a desrama artificial promove alterações na copa das árvores, por remover parte da biomassa da base da copa (galhos e folhas) (PULROLNIK, 2002; LIMA, 2003; ALMEIDA, 2003), podendo comprometer o crescimento das plantas, principalmente quando reduz drasticamente sua superfície fotossintetizante (LANGE et al., 1987; PINKARD e BEADLE, 1998; REIS et al., 2001). Povoamentos de eucalipto manejados para a produção de madeira de qualidade, através da desrama artificial, devem ser desbastados para a obtenção de árvores com maior diâmetro, aumentando a eficiência no desdobramento das toras. Estudos sobre desbastes em plantações de eucalipto no Brasil têm-se intensificado recentemente, em razão da crescente demanda de madeira para serraria, utilizando-se, principalmente, dados de crescimento em altura, diâmetro e volume (NOGUEIRA et al., 2001; LEITE et al., 2005; DIAS et al., 2005). O desbaste, assim como a desrama artificial, influenciam o formato e a dinâmica de copa das árvores do povoamento, pois disponibilizam mais recursos às plantas remanescentes, principalmente por aumentar a trasmitância da radiação solar através do dossel (YU et al., 2003; WHITEHEAD e BEADLE, 2004). Assim, a análise da dinâmica de copa das plantas auxilia as decisões silviculturais, de forma a otimizar o crescimento das plantas.

R. Árvore, Viçosa-MG, v.31, n.6, p.989-998, 2007
A dinâmica de copa pode ser avaliada por métodos diretos ou indiretos, utilizando-se sensores que permitam a determinação da radiação fotossinteticamente ativa, do índice de área foliar, fotografias do dossel ou determinação da biomassa dos componentes da copa. O método direto é o mais preciso para a obtenção da área foliar, porém mais trabalhoso e consome maior tempo para sua obtenção, não sendo, pois, recomendado, em termos operacionais, para mensuração de grandes áreas. É um método destrutivo e, em razão da elevada variação de área foliar entre plantas, demanda a amostragem de grande número de plantas em diferentes idades, porém é um método importante para a calibração de técnicas indiretas de obtenção do IAF (JONCKHEERE et al., 2004). Para a obtenção indireta do índice de área foliar, novos instrumentos e técnicas têm sido desenvolvidos, apresentando rapidez e facilidade para a coleta dos dados. Os analisadores de dossel obtêm o IAF por comparação diferencial entre a radiação abaixo e acima do dossel (JONCKHEERE et al., 2004). Fotografias hemisféricas também têm sido usadas em estudos de abertura do dossel (clareiras), arquitetura de copa e determinação do IAF (WANG e MILLER, 1987; HALE, 2003). Com o advento da tecnologia digital, melhorias das imagens digitais e desenvolvimento de softwares específicos e técnicas de análise de imagens digitais têm sido recentemente utilizadas para examinar fotografias do dossel (FRAZER et al., 2001; HALE e EDWARDS, 2002; HALE, 2003; ZHANG et al., 2005). A avaliação da radiação fotossinteticamente ativa e do índice de área foliar foi utilizada no Brasil por Pulrolnik (2002), Lima (2003)e Almeida (2003), para melhor entender a dinâmica de copa de plantas submetidas à desrama artificial.

O objetivo deste estudo foi caracterizar a dinâmica da copa de plantas do clone 24504 de Eucalyptus grandis 
submetida a desrama artificial e ao primeiro desbaste, através da análise de fotografias digitais, índice de área foliar e radiação fotossinteticamente ativa.

\section{MATERIAL E MÉTODOS}

Este trabalho foi desenvolvido em povoamento do clone 24504 de Eucalyptus grandis, estabelecido em novembro de 1998, no espaçamento 3 x 3 m, na Companhia Agrícola e Florestal Santa Bárbara (CAF), no Município de Abaeté, MG. A temperatura média anual é de $21^{\circ} \mathrm{C}$ e a precipitação média anual, de $1.314 \mathrm{~mm}$, com valor médio de déficit hídrico de $171 \mathrm{~mm}$ anuais e evapotranspiração potencial anual de $1.018 \mathrm{~mm}$, com base em dados coletados pela empresa, na região, no período de 1999 a 2003.

O experimento envolveu seis combinações de diferentes intensidades de desrama (altura de remoção dos galhos a partir do solo) e freqüência (número de intervenções necessárias para atingir $6 \mathrm{~m}$ de altura livre de galhos na planta), quando a primeira intervenção de desrama ocorreu aos 16 e 20 meses de idade (Tabela 1), e quatro combinações, quando a primeira intervenção ocorreu aos 28 meses de idade (Tabela 2). Aos 45 meses de idade, foi feita a intervenção de desrama nas plantas, retirando-se todos os galhos vivos e mortos entre 3 e $6 \mathrm{~m}$ de altura, para obtenção de uma segunda tora de $3 \mathrm{~m}$ livre de nós. Cada parcela foi constituída de quatro fileiras ao longo do talhão, em que 10 mudas plantadas em cada uma das duas fileiras centrais, a partir da quinta muda, constituíram a parcela útil para as avaliações da dinâmica da copa em seqüência de idade. Aos 55 meses de idade, procedeu-se ao desbaste até a $20^{\mathrm{a}}$. planta de cada linha, eliminando $35 \%$ do número total de mudas plantadas em cada parcela do experimento, o que correspondeu a aproximadamente $27 \%$ de remoção da área basal do povoamento. Procurou-se analisar a distribuição espacial das plantas a serem eliminadas para evitar a formação de grandes clareiras. O desbaste ocorreu independentemente das plantas estarem apresentando redução na sua taxa de crescimento, uma vez que o objetivo do trabalho era aplicar o desbaste após a recomposição da copa das plantas pelo menos ao nível do observado antes da última aplicação de desrama realizada aos 45 meses de idade, com base nos dados de índice de área foliar.

O experimento foi instalado no delineamento inteiramente casualizado, seguindo-se o esquema de parcelas subdivididas, sendo as parcelas constituídas pelos tratamentos de desrama e as subparcelas pelas idades de avaliação dos parâmetros da copa, para cada idade de primeira intervenção de desrama.

A dinâmica de copa das plantas submetidas a diferentes tratamentos de desrama artificial e de desbaste foi avaliada através do índice de área foliar (IAF), da transmitância da radiação fotossinteticamente ativa (t\%) e do índice de cobertura do dossel (ICD) obtido a partir de fotografia digital (Figura 1), aos 55 meses de idade, antes e imediatamente depois da realização do desbaste, e aos 68 meses de idade para cada uma das três idades de realização da primeira intervenção de desrama artificial, de modo a obter a permeabilidade relativa do dossel em uma seqüência de idade e, conseqüentemente, avaliar a recomposição da copa após o desbaste. Aos 61 meses de idade, em avaliação realizada em dezembro, foi estimado apenas o IAF, em razão da constante presença de nuvens, o que dificulta a medição da radiação e tomada de fotografias. Essas avaliações foram realizadas em três pontos por parcela, locados entre as duas linhas úteis de cada parcela do experimento, na interseção das diagonais que unem quatro árvores.

Tabela 1 - Tratamentos de desrama (intensidade e freqüência) aplicados em plantas do clone 24504 de Eucalyptus grandis, submetidas à primeira intervenção aos 16 meses e 20 meses de idade, em Abaeté, MG

Table 1 -Pruning treatments applied to Eucalyptus grandis clone plants starting at the age of 16 and 20 months, in Abaeté, MG

\begin{tabular}{|c|c|c|c|c|c|}
\hline \multirow[t]{2}{*}{ Tratamento } & \multicolumn{4}{|c|}{ Altura parcial de desrama (m) } & \multirow[t]{2}{*}{ Altura total de desrama $(\mathrm{m})$} \\
\hline & $16^{1}$ e $20^{1}$ meses & 20 e 28 meses & 28 e 33 meses & 45 meses & \\
\hline Testemunha & - & $\longrightarrow$ & $\longrightarrow$ & - & 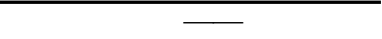 \\
\hline $0,5+0,5+2,0+3,0$ & $0,5^{2}$ & $0,5^{3}$ & $2,0^{3}$ & $3,0^{3}$ & 6,0 \\
\hline $0,5+1,0+1,5+3,0$ & 0,5 & 1,0 & 1,5 & 3,0 & 6,0 \\
\hline $1,0+1,0+1,0+3,0$ & 1,0 & 1,0 & 1,0 & 3,0 & 6,0 \\
\hline $1,0+0,0+2,0+3,0$ & 1,0 & - & 2,0 & 3,0 & 6,0 \\
\hline $1,5+0,0+1,5+3,0$ & 1,5 & - & 1,5 & 3,0 & 6,0 \\
\hline
\end{tabular}

116 e 20 meses constituem as idades de aplicação da primeira intervenção de desrama;

${ }^{2}$ Altura de desrama a partir do nível do solo; ${ }^{3}$ Altura de desrama a partir da intervenção anterior 
Quadro 2 - Tratamentos de desrama aplicados em plantas do clone 24504 de Eucalyptus grandis na primeira intervenção, aos 28 meses de idade, em Abaeté, MG

Table 2 - Pruning treatments applied to Eucalyptus grandis clone plants starting at the age of 28 months, in Abaeté, MG

\begin{tabular}{|c|c|c|c|c|}
\hline \multirow[t]{2}{*}{ Tratamento } & \multicolumn{3}{|c|}{ Altura parcial de desrama $(\mathrm{m})$} & \multirow[t]{2}{*}{ Altura total de desrama $(\mathrm{m})$} \\
\hline & 28 meses & 33 meses & 45 meses & \\
\hline Testemunha & - & - & - & $\longrightarrow$ \\
\hline $1,0+2,0+3,0$ & $1,0^{1}$ & $2,0^{2}$ & $3,0^{2}$ & 6,0 \\
\hline $1,5+1,5+3,0$ & 1,5 & 1,5 & 3,0 & 6,0 \\
\hline $3,0+0,0+3,0$ & 3,0 & 0,0 & 3,0 & 6,0 \\
\hline
\end{tabular}

${ }^{1}$ Altura de desrama a partir do nível do solo; ${ }^{2}$ Altura de desrama a partir da intervenção anterior
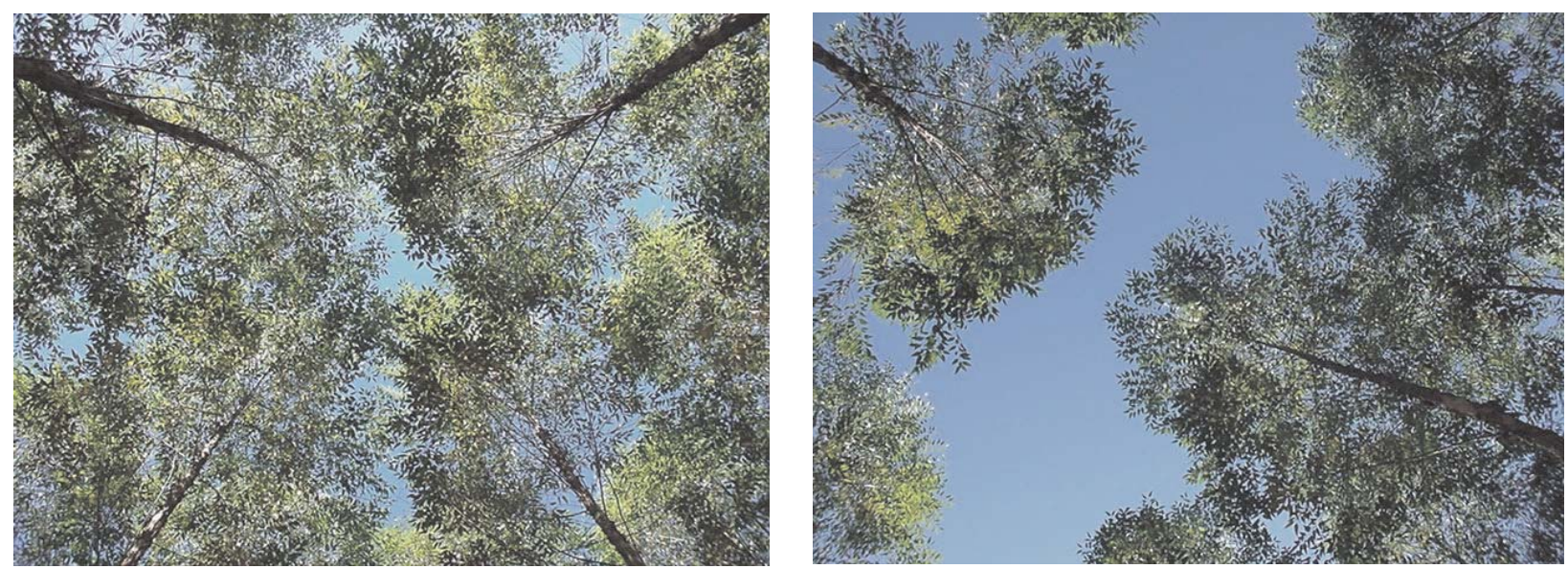

Figura 1 - Fotografias digitais obtidas numa mesma posição da parcela experimental, antes (foto à esquerda) e depois (foto à direita) a realização do desbaste.

Figure 1 -Digital photographs obtained in the same position of the experimental plot before (left) and after (right) thinning.

Para a estimativa do IAF foram utilizados dois sensores LI-2050, conectados a dataloggers LI-2000 da LI-COR, sendo um instalado em área aberta e outro usado para obtenção dos dados no interior das parcelas. As leituras foram realizadas sob luz difusa, ao amanhecer e ao final da tarde. A radiação fotossinteticamente ativa (RFA) foi medida com sensores lineares (modelo LI191, marca LI-COR) conectados a registradores automáticos, para as leituras dentro do povoamento florestal. Cada valor foi resultado da leitura dos sensores durante dois minutos em cada ponto. Em área aberta, foi instalado um sensor pontual, modelo LI-190, marca LI-COR, a fim de obter a RFA a céu aberto. As leituras foram realizadas entre 11 e $13 \mathrm{~h}$, a $0,5 \mathrm{~m}$ do solo, preferencialmente em dias sem nuvens. Para o cálculo da transmitância da RFA (t\%), foi utilizada a seguinte expressão: $\mathrm{t} \%=\left(\mathrm{RFA}_{\mathrm{A}} / \mathrm{RFA}_{\mathrm{B}}\right) \times 100$, em que $\mathrm{t} \%=$ transmitância da radiação fotossinteticamente ativa $(\%) ; \mathrm{RFA}_{\mathrm{A}}=$ radiação fotossinteticamente ativa abaixo do dossel; e $\mathrm{RFA}_{\mathrm{B}}=$ radiação fotossinteticamente ativa a céu aberto. A estimativa do índice de cobertura do dossel (ICD) se deu através da obtenção de fotografias digitais no tamanho $640 \times 480$ pixels, utilizando uma câmera fotográfica digital Sony MVC FD88, direcionada para a copa das árvores e posicionada ao nível do solo, buscando obter detalhes das copas em maior campo de visão. Cada fotografia foi processada pelo programa ERDAS IMAGINE, versão 8.5, para obter o porcentual de cobertura do dossel em cada tratamento.

Aos 68 meses de idade, foi realizada a medição dos três parâmetros de copa acima descritos em área não-desbastada contendo os mesmos tratamentos de desrama artificial, com três repetições, para comparação com os dados da área desbastada, em delineamento inteiramente casualizado, em esquema fatorial $6 \times 2$ (tratamentos de desrama e de desbaste) para a idade da primeira intervenção correspondente a 16 e 20 meses e 4 x 2 para a idade da primeira intervenção correspondente a 28 meses. 
Os dados de IAF, $\mathrm{t} \%$ e ICD para cada idade de primeira intervenção de desrama foram avaliados através da análise de variância. Quando houve diferença significativa entre os tratamentos de desrama, idades de avaliação ou interação entre eles, em nível de 5\% de probabilidade, aplicouse o teste de Tukey para comparação das médias, também em nível de $5 \%$ de probabilidade.

\section{RESULTADOS E DISCUSSÃO}

\section{1. Índice de área foliar}

Este índice, obtido aos 55, 61 e 68 meses de idade, não variou significativamente $(\mathrm{P} \geq 0,05)$ entre os tratamentos de desrama artificial, e também não foi observada interação significativa entre tratamentos de desrama artificial e idade de avaliação do IAF, em plantas cuja primeira intervenção de desrama ocorreu aos 16, 20 e 28 meses de idade, porém foram observadas diferenças entre as idades de avaliação do IAF, conforme resultados da análise de variância. Lima (2003) também não observou diferenças significativas no IAF entre tratamentos de desrama artificial, em plantas desse mesmo povoamento, aos 45 meses de idade, em razão da elevada capacidade de recomposição de copa do clone 24504, mesmo após a retirada de elevada proporção de copa viva da planta.

Logo após a realização do desbaste, aos 55 meses de idade, no período seco do ano, houve aumento da abertura do dossel, com consequiente redução significativa do IAF, conforme teste de Tukey $(\mathrm{P} \leq 0,05)$, com sua recuperação significativa aos 61 meses de idade, pelo menos no mesmo nível do IAF observado antes do desbaste, nas três idades de primeira intervenção de desrama (Tabela 3). O valor médio geral de IAF, nas três idades de primeira intervenção de desrama, reduziu de 2,75 para 1,98, após o desbaste, o que corresponde a uma redução de $28,0 \%$. Aos 61 meses de idade, foi observada acentuada recomposição foliar das plantas, atingindo IAF médio geral de 2,99, valor $51,0 \%$ maior que o verificado aos 55 meses, imediatamente depois do desbaste. A avaliação aos 61 meses de idade foi realizada em dezembro, início do período chuvoso na região, indicando que a recomposição de copa é imediata com o advento do período chuvoso.

Tabela 3 - Valores médios de índice de área foliar, transmitância da RFA e índice de cobertura do dossel aos 55 (antes e depois do desbaste), 61 e 68 meses de idade, em povoamento do clone 24504 de Eucalyptus grandis submetido à primeira intervenção de desrama artificial aos 16, 20 e 28 meses de idade e desbaste aos 55 meses de idade, em Abaeté-MG

Table 3 - Leaf area index, photosynthetic active radiation transmitance and crown cover index at the age of 55 (before and after thinning), 61-and 68-month-old Eucalyptus grandis clone stands submitted to pruning at the age of 16, 20 and 28 months, and thinning at the age of 55 months, in Abaeté, MG

\begin{tabular}{|c|c|c|c|c|c|c|c|c|c|c|c|c|c|}
\hline \multirow[t]{2}{*}{$\begin{array}{c}\text { Altura de } \\
\text { desrama (m) }\end{array}$} & \multicolumn{4}{|c|}{$\begin{array}{l}\text { Índice de } \\
\text { Área Foliar }\end{array}$} & \multirow[t]{2}{*}{$\mathrm{CV} \%$} & \multicolumn{3}{|c|}{$\begin{array}{c}\text { Transmitância } \\
\text { da RFA }\end{array}$} & \multirow[t]{2}{*}{$\mathrm{CV} \%$} & \multicolumn{3}{|c|}{$\begin{array}{l}\text { Índice de Cobertura } \\
\text { de Dossel }\end{array}$} & \multirow[t]{2}{*}{$\mathrm{CV} \%$} \\
\hline & $55^{1}$ & $55^{2}$ & $61^{2}$ & $68^{2}$ & & $55^{1}$ & $55^{2}$ & $68^{2}$ & & $55^{1}$ & $55^{2}$ & $68^{2}$ & \\
\hline \multicolumn{14}{|c|}{ Primeira intervenção aos 16 meses } \\
\hline Testemunha & 2,57 & 1,89 & 3,09 & 3,40 & & 7,7 & 15,7 & 13,6 & & 0,82 & 0,68 & 0,71 & \\
\hline $0,5+0,5+2,0+3,0$ & 2,64 & 1,90 & 2,89 & 3,24 & & 11,9 & 36,4 & 17,4 & & 0,84 & 0,72 & 0,68 & \\
\hline $0,5+1,0+1,5+3,0$ & 2,53 & 1,91 & 3,08 & 3,41 & & 24,7 & 26,5 & 18,8 & & 0,85 & 0,69 & 0,73 & \\
\hline $1,0+1,0+1,0+3,0$ & 2,57 & 1,90 & 3,06 & 3,37 & & 12,2 & 14,1 & 15,6 & & 0,83 & 0,68 & 0,72 & \\
\hline $1,0+0,0+2,0+3,0$ & 2,75 & 1,88 & 2,59 & 3,29 & & 8,0 & 23,6 & 23,9 & & 0,84 & 0,68 & 0,71 & \\
\hline $1,5+0,0+1,5+3,0$ & 2,87 & 1,89 & 2,74 & 3,27 & & 7,4 & 20,1 & 11,3 & & 0,83 & 0,72 & 0,74 & \\
\hline Média & $2,66 b$ & $1,90 \mathrm{c}$ & $2,91 \mathrm{ab}$ & $3,33 \mathrm{a}$ & 9,23 & $11,9 \mathrm{~b}$ & $22,7 \mathrm{a}$ & $16,8 \mathrm{ab}$ & 55,25 & $0,84 \mathrm{a}$ & $0,70 \mathrm{~b}$ & $0,72 b$ & 17,35 \\
\hline \multicolumn{14}{|c|}{ Primeira intervenção aos 20 meses } \\
\hline Testemunha & 2,82 & 2,04 & 3,16 & 3,25 & & & & 13.6 & & 0,82 & 0,68 & 0,71 & \\
\hline $0,5+0,5+2,0+3,0$ & 3,00 & 2,16 & 2,74 & 2,66 & & & & 20.9 & & 0,83 & 0,69 & 0,71 & \\
\hline $0,5+1,0+1,5+3,0$ & 3,00 & 2,17 & 2,94 & 2,70 & & & & 12.3 & & 0,84 & 0,68 & 0,72 & \\
\hline $1,0+1,0+1,0+3,0$ & 3,02 & 2,18 & 2,77 & 2,68 & & & & 16.1 & & 0,83 & 0,69 & 0,72 & \\
\hline $1,0+0,0+2,0+3,0$ & 2,85 & 2,06 & 2,98 & 2,71 & & & & 12.4 & & 0,83 & 0,68 & 0,73 & \\
\hline $1,5+0,0+1,5+3,0$ & 2,78 & 2,00 & 2,91 & 2,81 & & & & 16.7 & & 0,84 & 0,68 & 0,69 & \\
\hline Média & $2,91 \mathrm{a}$ & $2,10 \mathrm{~b}$ & $2,92 \mathrm{a}$ & $2,80 \mathrm{a}$ & 7,35 & & & 15,4 & & $0,83 \mathrm{a}$ & $0,68 \mathrm{~b}$ & $0,71 \mathrm{~b}$ & 14,64 \\
\hline \multicolumn{14}{|c|}{ Primeira intervenção aos 28 meses } \\
\hline Testemunha & 2,82 & 2,04 & 3,16 & 3,25 & & & & 13.6 & & 0,82 & 0,68 & 0,71 & \\
\hline $1,0+2,0+3,0$ & 2,56 & 1,85 & 3,23 & 3,26 & & & & 17.9 & & 0,77 & 0,66 & 0,66 & \\
\hline $1,5+1,5+3,0$ & 2,57 & 1,86 & 3,24 & 3,25 & & & & 12.7 & & 0,76 & 0,68 & 0,61 & \\
\hline $3,0+0,0+3,0$ & 2,65 & 1,91 & 3,24 & 3,27 & & & & 18.9 & & 0,78 & 0,69 & 0,69 & \\
\hline Média & $2,65 \mathrm{~b}$ & $1,92 \mathrm{c}$ & $3,22 \mathrm{a}$ & $3,26 \mathrm{a}$ & 4,87 & & & 15,8 & & $0,78 \mathrm{a}$ & $0,68 \mathrm{~b}$ & $0,67 \mathrm{~b}$ & 14,97 \\
\hline Média geral & 2,75 & 1,98 & 2,99 & 3,11 & & & & 16,0 & & 0,82 & 0,69 & 0,70 & \\
\hline
\end{tabular}

Médias seguidas pela mesma letra na mesma linha para cada parâmetro não diferem entre si, pelo teste de Tukey a 5\% de probabilidade.

${ }^{1}$ Medições antes da realização do desbaste e ${ }^{2}$ Medições depois da realização do desbaste. 
A recomposição do dossel, com base em dados de IAF, evidencia que as plantas investiram na produção de folhas, restabelecendo o seu aparato fotossintético, de modo a permitir o aproveitamento dos recursos, especialmente a radiação fotossinteticamente ativa, que é aumentada nas partes mediana e basal da copa das plantas após o desbaste (YU et al., 2003; WHITEHEAD e BEADLE, 2004). Lima (2003) relatou a alta capacidade de recomposição de copa do clone em estudo, logo após a aplicação de tratamentos de desrama artificial. Essa autora observou que a aplicação de desrama, aos 16 meses de idade, até a altura de 0,5; 1,0; e 1,5 m, em plantas desse mesmo povoamento, corresponde a uma redução de 43,58 e $81 \%$ do IAF, respectivamente, ressaltando-se que dois meses mais tarde as plantas dos dois primeiros tratamentos apresentaram recomposição total do dossel e as do último tratamento, embora com remoção drástica de copa, exibiram recomposição quase que total do IAF. Pinkard et al. (1999) também observaram que com a remoção de $70 \%$ da copa viva de Eucalyptus nitens não houve recomposição total da copa, enquanto com a remoção de $50 \%$ ocorreu a sua recomposição. Almeida (2003) aplicou desrama artificial envolvendo redução de no máximo $50 \%$ do IAF em povoamentos de três clones de Eucalyptus grandis x E. urophylla, no sul da Bahia, e observou recomposição total do dossel seis meses após a aplicação da desrama. Plantas desramadas de Acacia melanoxylon, que tiveram remoção de $50 \%$ de sua área foliar, apresentaram capacidade fotossintética significativamente mais elevada do que as não-desramadas até 40 semanas após a desrama (MEDHURST et al., 2006), o que, segundo esses autores, ocorreu em razão de aumento na taxa de translocação dos fotoassimilados das folhas remanescentes para a reposição das folhas removidas. Porém, com o desbaste a recomposição rápida da cobertura do dossel pode ocorrer em razão de aumento de incidência de radiação nas porções inferiores da copa das plantas, que antes estavam fotossintetizando abaixo da sua capacidade. Com o aumento da fixação de carbono nessa porção da copa haverá maior translocação de fotoassimilados para folhas novas, promovendo o fechamento do dossel.

Não foi observada diferença substancial no IAF entre 61 e 68 meses de idade, em razão da avaliação aos 68 meses ter sido realizada em julho, quando as plantas já se encontravam sob estresse hídrico, tendo possivelmente ocorrido estabilização na produção de folhas, podendo, até mesmo, ter ocorrido alguma queda de folhas nesse período. Variação substancial de IAF em função da disponibilidade hídrica foi observada em floresta nativa de E. maculata, tendo atingido apenas 0,7 em períodos de deficiência hídrica e aumentado para 5,0 na estação chuvosa, ao longo de um período de 15 anos, na Austrália (POOK et al., 1997), o que indica que a interpretação de resultados de IAF deve levar em conta a disponibilidade hídrica.

Entre 55 e 68 meses de idade, observou-se recuperação do IAF pelo menos nos níveis dos valores obtidos antes da aplicação do desbaste na primeira intervenção de desrama artificial aos 20 meses de idade, em que, quando a primeira intervenção ocorreu aos 16 e 28 meses de idade, os valores de IAF aos 68 meses foram significativamente superiores aos obtidos aos 55 meses de idade (Tabela 3). Em comparação com o IAF obtido imediatamente após o desbaste, observouse aumento médio de $57 \%$ nesse mesmo período, considerando a média das três idades de primeira intervenção de desrama.

Comparando-se a média geral do IAF da área nãodesbastada aos 68 meses de idade $(4,02)$ (Tabela 4) com o IAF aos 55 meses antes da aplicação do desbaste $(2,75)$ (Tabela 3$)$, o aumento de IAF foi de $46 \%$, portanto inferior aos $57 \%$ observados no povoamento desbastado, que passou de 1,98 imediatamente após o desbaste para 3,11 aos 68 meses de idade. Esse resultado indica haver competição mais elevada entre plantas no povoamento não-desbastado em relação ao desbastado. Considerando a possibilidade de aumento na produção de folhas na área desbastada continuar com taxa mais elevada do que na área não-desbastada, é provável que, em pouco tempo, essas duas áreas apresentem IAF's similares.

Conforme resultados da análise de variância, aos 68 meses de idade foi observada diferença significativa $(\mathrm{P} \leq 0,05)$ no IAF entre a área desbastada e a nãodesbastada, nas três idades da primeira intervenção de desrama. Porém, não houve diferença significativa entre os tratamentos de desrama artificial e não foi observada interação significativa entre tratamentos de desrama e desbaste. Os dados médios da área desbastada e não-desbastada, aos 68 meses de idade, são apresentados no Quadro 4. Em área não-desbastada, a média geral do IAF nas três idades da primeira intervenção de desrama foi de 4,02, enquanto em área

\section{R. Árvore, Viçosa-MG, v.31, n.6, p.989-998, 2007}


desbastada foi de 3,11 , ou seja, 29,3\% mais elevado do que na área desbastada. Uma maior aproximação dos valores de IAF em povoamentos desbastados e não-desbastados pode indicar a necessidade de nova intervenção de desbaste para permitir a manutenção de pleno desenvolvimento das plantas remanescentes.

O valor de IAF observado na área não-desbastada $(4,02)$ ainda pode aumentar se houver manutenção da qualidade do sítio, pois alguns autores encontraram valores de IAF em povoamentos de eucalipto mais elevados do que o observado neste estudo. Por exemplo, Pinkard et al. (1999) encontraram valores de IAF iguais a 6,0 em plantio de E. nitens aos 3 anos de idade, e Dye e Olbrich (1993) observaram IAF de 4,5 em povoamento de E. grandis com 6 anos, na África. Devese ressaltar que o IAF pode variar com o material genético, a qualidade do sítio e o manejo do povoamento, dentre outros, ressaltando-se que, usualmente, o IAF é mais elevado especialmente em plantações manejadas com adubação e, ou, irrigação (WHITEHEAD e BEADLE, 2004). O IAF máximo observado no povoamento deste estudo, antes da realização do desbaste, foi 3,14 (LIMA, 2003), em avaliação realizada ao final do período chuvoso, quando, usualmente, o IAF é mais elevado. Considerando que esta pesquisa foi desenvolvida na região de Cerrado, cujos solos apresentam fertilidade natural baixa e extenso período de deficiência hídrica no solo, haveria a necessidade de aplicação de adubação após o desbaste, para permitir a manutenção de IAF elevado, o que favoreceria o crescimento das plantas.

\subsection{Transmitância da radiação fotossinteticamente ativa}

A transmitância da radiação fotossinteticamente ativa $(\mathrm{t} \%)$ não diferiu significativamente entre tratamentos de desrama artificial, e não foi observada interação significativa entre tratamentos de desrama e idade de avaliação de $t \%$, quando a primeira intervenção de desrama ocorreu aos 16 meses de idade. Porém, foi notada diferença significativa entre as idades de avaliação (Tabela 3), em nível 5\% de probabilidade, assim como o foi nos valores de IAF. Não foi possível realizar a análise dos dados de $t \%$ do povoamento submetido à primeira intervenção de desrama artificial aos $20 \mathrm{e}$ 28 meses de idade, em povoamento desbastado, em razão de terem ocorrido problemas com os equipamentos por ocasião da coleta de dados aos 55 meses de idade, antes e depois do desbaste.
Tabela 4 - Valores médios de índice de área foliar, transmitância da RFA e índice de cobertura do dossel, aos 68 meses de idade, em povoamento do clone 24504 de Eucalyptus grandis submetido à primeira intervenção de desrama artificial aos 16, 20 e 28 meses de idade, em povoamentos desbastados e não-desbastados, em Abaeté-MG

Table 4 - Leaf area index, photosynthetic active radiation transmitance and crown cover index at the age of 55, 61 and 68 months of Eucalyptus grandis clone stands submitted to pruning at the age of 16, 20 and 28 months, in thinned and non-thinned stands, in Abaeté, $M G$

\begin{tabular}{|c|c|c|c|}
\hline $\begin{array}{l}\text { Idade da primeira } \\
\text { intervenção }\end{array}$ & Desbastado & $\begin{array}{l}\text { Não } \\
\text { sbasta }\end{array}$ & $\mathrm{CV} \%$ \\
\hline (meses) & \multicolumn{3}{|c|}{ Índice de Área Foliar } \\
\hline 16 & 3,33 & 4,37 & 6,94 \\
\hline 20 & 2,80 & 3,96 & 3,45 \\
\hline 28 & 3,26 & 3,59 & 6,11 \\
\hline \multirow[t]{2}{*}{ Média Geral } & 3,11 & 4,02 & \\
\hline & \multicolumn{3}{|c|}{ Transmitância da RFA } \\
\hline 16 & 16,8 & 8,8 & 59,16 \\
\hline 20 & 15,4 & 10,9 & 44,52 \\
\hline 28 & 15,8 & 8,6 & 55,72 \\
\hline \multirow[t]{2}{*}{ Média Geral } & 16,0 & 9,6 & \\
\hline & \multicolumn{3}{|c|}{ Índice de Cobertura de Dossel } \\
\hline 16 & 0,72 & 0,80 & 15,97 \\
\hline 20 & 0,71 & 0,80 & 17,54 \\
\hline 28 & 0,67 & 0,77 & 18,83 \\
\hline Média Geral & 0,70 & 0,79 & \\
\hline
\end{tabular}

Aos 55 meses de idade, antes do desbaste a transmitância da radiação fotossinteticamente ativa média foi de $11,9 \%$, quando a primeira intervenção de desrama ocorreu aos 16 meses de idade, e logo após a realização do desbaste t\% atingiu 22,7 \% (Tabela 3), ou seja, praticamente dobrou, com redução de $27 \%$ na área basal do povoamento. Aos 68 meses de idade, a transmitância diminuiu para $16,8 \%$ (26,4\% de redução em relação ao obtido após o desbaste), não atingindo o valor observado antes do desbaste $(11,9 \%)$, contrastando com o IAF (Tabela 3 ), que se equiparou a valores observados antes do desbaste.

Aos 68 meses de idade (Tabela 4), houve diferença significativa para t\%, entre a área desbastada e a nãodesbastada, não tendo sido observado diferença entre os tratamentos de desrama artificial. Em área desbastada, a média geral foi de $16,0 \%$, enquanto em área nãodesbastada foi de $9,6 \%$, ou seja, $40,3 \%$ superior em área desbastada, indicando que até essa idade ainda não houve fechamento do dossel.

R. Árvore, Viçosa-MG, v.31, n.6, p.989-998, 2007 
O desbaste promove descontinuidade do dossel, e, segundo Hale (2003), nessa condição a aplicação da Lei de Beer é comprometida, porque a radiação solar é transmitida principalmente através das aberturas promovidas pela remoção de árvores, em invés de ser através de uma camada contínua de folhas. Esse autor observou que o coeficiente de extinção da radiação solar em área desbastada reduziu-se pela metade. Isso explica o elevado aumento da t\% após a realização do desbaste, nesta pesquisa. Para que haja redução substancial na radiação solar que chega ao piso da floresta, haverá, então, a necessidade de expansão lateral da copa das árvores, preenchendo as aberturas do dossel promovidas pelo desbaste. Entre 55 e 68 meses de idade não foi observada expressiva expansão lateral da copa, tendo ocorrido, principalmente, aumento na altura da copa viva. Também, ao contrário do que houve com o índice de área foliar, a produção de outros componentes como galhos e tronco não aumenta substancialmente após o desbaste, a ponto de atenuar significativamente a radiação que passa através do dossel.

$\mathrm{O}$ aumento na t\% após o desbaste e, inclusive, após a desrama promove maior exposição das folhas da copa das porções mediana e basal à radiação solar (YU et al., 2003; WHITEHEAD e BEADLE, 2004), podendo, inclusive, haver aumento na fixação de carbono no nível da folha, conforme observado em $E$. nitens após desrama artificial (PINKARD et al., 1998), porque a taxa fotossintética não se encontrava em seu máximo, em razão do auto-sombreamento na parte basal da copa. Dessa forma, as florestas submetidas a desrama e desbaste devem ser manejadas para que as plantas exibam máxima fixação de carbono e elevada produção de madeira de qualidade superior, uma vez que essas operações silviculturais são onerosas.

\section{3. Índice de cobertura do dossel}

O índice de cobertura do dossel (ICD) não variou significativamente com a desrama artificial, resultado similar ao obtido para IAF e t\%. Houve, porém, diferença no ICD em relação ao tratamento de desbaste (Tabela 4).

Aos 55 meses de idade, o ICD médio decresceu significativamente de 0,82 para 0,69 com o desbaste, o que corresponde a uma redução de 16,9\%. Aos 68 meses de idade, o ICD foi apenas $1 \%$ superior ao observado após a realização do desbaste. Aos 68 meses de idade, houve diferença significativa no índice de cobertura vegetal entre a área desbastada $(0,70)$ e a não-desbastada $(0,79)$, sendo $9,0 \%$ inferior ao da área desbastada. Esses resultados relativos a mudanças no ICD com o desbaste e idade do povoamento contrastam com os dados obtidos de IAF e t\% que resultaram em maior diferenciação em razão do desbaste.

A tendência de pequena variação nos valores de ICD após a aplicação de desbaste no povoamento deste estudo indicou que a metodologia de tomada de fotografias digitais para essa finalidade ainda necessita de aperfeiçoamentos. Zhang et al. (2005) demonstraram que fotografias digitais hemisféricas não devem ser tomadas com exposição automática, sendo necessário aumentar o contraste entre a copa e o céu para obter melhor correlação entre os valores de índice de área foliar determinados com analisadores de dossel e fotografias digitais. O uso de fotografias hemisféricas, tiradas com exposição automática corrigida, apresentou baixa capacidade de diferenciar a copa e o céu, em comparação com o uso do ceptômetro, em povoamentos de Picea sitchensis sob diferentes intensidades de desbaste, principalmente quando os níveis de transmitância da radiação foram relativamente baixos (HALE, 2003). Neste trabalho, as fotografias digitais foram tiradas com exposição automática, podendo constituir-se em uma das causas da baixa sensibilidade do método. Os estudos anteriormente referidos foram realizados em povoamentos de coníferas que apresentam dinâmica de copa diferente daquela observada em eucalipto, havendo, portanto, necessidade de considerar alterações na metodologia de tomada dessas fotos.

Esses resultados indicam que o uso de fotografias digitais para determinação do índice de cobertura do dossel é menos sensível às mudanças do desenvolvimento da copa após o desbaste do que o uso do índice de área foliar, obtido através de medidas com analisador de dossel, bem como do uso da transmissividade da radiação fotossinteticamente ativa.

A obtenção de fotografias digitais com lente convencional tem grande potencial para sua utilização em estudos de dinâmica de copa, com a vantagem de ser um método mais barato que a utilização de lentes tipo "olho de peixe", embora esta última seja mais precisa, por proporcionar fotografias com maior ângulo de visão. O uso de fotografias digitais é, também, vantajoso em relação aos métodos utilizando IAF e t\%, que demandam equipamentos de elevado custo e de difícil uso e manutenção, desde que sejam realizados ajustes na metodologia de uso dessas fotografias digitais. 


\section{CONCLUSÕES}

1. O clone estudado apresentou elevada capacidade de recomposição de copa, após a aplicação de desbaste, em que, imediatamente após o desbaste, houve redução de $28 \%$ no índice de área foliar e seis meses depois foi observado aumento de $51 \%$ no IAF.

2. O índice de área foliar foi considerado o parâmetro mais seguro para utilização em estudos de dinâmica de copa, pois apresentou dados consistentes, com baixo coeficiente de variação.

3. A transmitância da radiação fotossinteticamente ativa pode ser usada em estudos de avaliação de recomposição de área foliar em povoamentos florestais, porém, a qualidade dos dados obtidos depende da obtenção de condições ambientais específicas, sendo requerido, dentre outros, a existência de céu aberto, sem qualquer nebulosidade, no momento da leitura.

4. A utilização de fotografias digitais apresenta elevado potencial em estudo de dinâmica de copa, em razão de ser um método mais barato que os demais utilizados neste estudo, porém o uso desse recurso ainda requer aperfeiçoamentos.

\section{REFERÊNCIAS}

ALMEIDA, M. L. Desrama artificial em clones de híbridos de Eucalyptus grandis x E. urophylla com diferenças em arquitetura de copa. 2003. 119p. Dissertação (Mestrado em Ciência Florestal) - Universidade Federal de Viçosa, Viçosa, MG, 2003.

DIAS, A. D. et al. Emprego de um modelo de crescimento e produção em povoamentos desbastados de eucalipto. Revista Árvore, v.29, n.5, p.731-739, 2005.

DYE, P. J.; OLBRICH, B. W. Estimating transpiration from 6-year-old Eucalyptus grandis trees: Development of a canopy conductance model and comparison with independent sap flux measurements. Plant Cell and

Environment, v.16, p.45-53, 1993.

FRAZER, G. W.; TROFYMOV, J. A.; LERTZMAN, K. P. Canopy openness and leaf area in chronosequences of coastal temperate rainforests. Canadian Journal of Forest Research, v.30, p.239-256, 2001.
HALE, S. E. The effect of thinning intensity on the below-canopy light environment in a Sitka spruce plantation. Forest Ecology and Management, v.179, p.341-349, 2003.

HALE, S. E.; EDWARDS, C. Comparison of film and digital hemispherical photography across a wide range of canopy densities. Agricultural and Forest Meteorology, v.112, p.51-56, 2002.

JONCKHEERE, I. et al. Review of methods for in situ leaf area index determination - Part I. Theories, sensors and hemispherical photography. Agricultural and Forest Meteorology, v.121, p.19-35, 2004.

LANGE, P. W.; RONDE, C.; BREDENKAMP, B. V. The effects of different intensities of pruning on the growth of Pinus radiata in South Africa.

South African Forestry Journal, v.143, p.30-36, 1987.

LEITE, H. G. et al. Avaliação de um modelo de distribuição diamétrica ajustado para povoamento de Eucalyptus sp. submetidos a desbaste.

Revista Árvore, v.29, n.2, p.271-280, 2005.

LIMA, A. P. L. Aplicação de desrama em clone de Eucalyptus grandis em diferentes épocas e intensidade: efeitos sobre o crescimento e dinâmica de copa. 2003. 195f. Tese (Doutorado em Ciência Florestal) - Universidade Federal de Viçosa, Viçosa, MG, 2003.

MEDHURST, J. L. et al. Photosynthetic capacity increases in Acacia melanoxylon following form pruning in a two-species plantation. Forest Ecology and Management, v.233, p.250-259, 2006.

NOGUEIRA, G. S. et al. Determinação da idade técnica de desbaste em plantações de eucalipto, utilizando o método dos ingressos percentuais. Scientia Forestalis, n.59, p.51-59, 2001.

PINKARD, E. A. et al. Modelling the effect of physiological responses to green pruning on net biomass production of Eucalyptus nitens (Deane and Maiden) Maiden. Tree Physiology, v.19, p.1-12, 1999.

R. Árvore, Viçosa-MG, v.31, n.6, p.989-998, 2007 
PINKARD, E. A.; BEADLE, C. L. Effects of green pruning on growth and stem shape of Eucalyptus nitens (Deane and Maiden) Maiden. New

Forest, v.15, p.107-126, 1998.

PIRES, B. M. Efeito da desrama

artificial no crescimento e

qualidade da madeira de Eucalyptus

grandis para serraria e fabricação de móveis. 2000. 96p. Dissertação (Mestrado em Ciência Florestal) - Universidade Federal de Viçosa, Viçosa, MG, 2000.

POLLI, H. Q. et al. Qualidade da madeira em clone de Eucalyptus grandis Hill ex Maiden submetido a desrama artificial. Revista Árvore, v.30, n.4, p.557-566, 2006.

POOK, E. W.; GILL, A. M.; MOORE, P. H. R. Long-term variation of litter fall, canopy leaf area and flowering in a Eucalyptus maculata forest on the south coast of New South Wales. Australian Journal of Botany, v.45, p.737-755, 1997.

PULRolniK, K. Crescimento, dinâmica de copa e qualidade da madeira de clone de Eucalyptus grandis [Hill ex Maiden] submetido à desrama artificial. 2002. 96f. Dissertação (Mestrado em Ciência Florestal) Universidade Federal de Viçosa, Viçosa, MG, 2002.
REIS, M. G. F. et al. Effect of artificial pruning on Eucalyptus grandis growth in southeastern Brazil. In: IUFRO INTERNATIONAL SYMPOSIUM:

Developing the Eucalypt of Future, 2001, Valdivia. Proceedings... Valdivia: 2001 CD-ROM.

VALE, R. S. et al. Efeito da desrama artificial na qualidade da madeira de clones de eucalipto em sistema agrosilvipastoril. Revista Árvore, v.26, n.3, p.285-297, 2002.

WANG, Y. S.; MILLER, D. R. Calibration of the hemispherical photography technique to measure leaf area index distributions in hardwood forests. Forest Science, v.33, p.210-216, 1987.

WHITEHEAD, D.; BEADLE, C. L. Physiological regulation of productivity and water use in Eucalyptus: A review. Forest Ecology and Management, v.193, p.113-140, 2004.

YU, S. et al. Crown characteristics of juvenile loblolly pine 6 years after application of thinning and fertilization. Forest Ecology and Management, v.180, p.345-352, 2003.

ZHANG, Y.; CHEN, J. M.; MILLER, J. R. Determining digital hemispherical photograph exposure for leaf area index estimation.

Agricultural and Forest Meteorology, v.133, p.166-181, 2005. 